\title{
Çeşitli Katyon Değiştirilmiş ve Sütunlanmış Artvin Bentonitlerinin Karakterizasyonu ve Seçilmiş Bir Organik Reaksiyonda Katalizör Olarak Kullanılmaları
}

\author{
Ahmet Tabak $^{1 *}$, Bülent Çăglar ${ }^{2}$, Mehmet Kaya ${ }^{3} \odot$ \\ ${ }^{1 *}$ Sinop Üniversitesi Fen-Edebiyat Fakültesi Kimya Bölümü, Sinop, Türkiye; \\ ${ }^{2}$ Erzincan Binali Yıldırım Üniversitesi Fen-Edebiyat Fakültesi Kimya Bölümü, ${ }^{3}$ Erzincan, Türkiye; \\ ${ }^{3}$ Recep Tayyip Erdoğan Üniversitesi Fen-Edebiyat Fakültesi Kimya Bölümü, Rize, Türkiye
}

Geliş / Received: 12/02/2020, Kabul / Accepted: 20/02/2020

\begin{abstract}
$\ddot{O} \mathbf{z}$
$\mathrm{Bu}$ çalışmada Artvin ham bentonitinin, bazı metal katyonları $\left(\mathrm{Fe}^{3+}\right.$ ve $\left.\mathrm{Cu}^{2+}\right)$ değiştirilmiş ve $\mathrm{Fe}$ - ve $\mathrm{Al}-$ sütunlanmış türevlerinin benzaldehitin 2,3-bütandiol ile asetalleşme reaksiyonundaki katalitik aktiviteleri araştırıldı. Bu katalizörlerin yapısal ve fizikokimyasal özellikleri X-1şılları toz kırınım (XRD), taramalı elektron mikroskobu (SEM), Fourier transform infrared (FTIR), ve yüzey alanı ölçüm teknikleri yardımıyla aydınlatılmıştır. $\mathrm{Cu}$-bentonit ve $\mathrm{Al}$ sütunlu-bentonit katalizörlü reaksiyonlarda verimin çok az olduğu buna karşın Fe-bentonit ve Fe-sütunlu bentonit katalizörlerinin kullanıldı̆̆ tepkimelerde ise sirasılyla \% 60 ve \% 63 verimle asetalleşme reaksiyonu gerçekleştiği tespit edilmiştir. $\mathrm{Bu}$ çalışma ülkemizin önemli yerli kaynaklarından birini teşkil eden Artvin bentonitinin modifiye edilmesiyle organik reaksiyonları katalizleyebildiğini ve bu ürünlerin küçük ölçekte ve endüstriyel proseslerdeki reaksiyonlar için kullanılabileceğini ortaya koymuştur.
\end{abstract}

Anahtar Kelimeler: Artvin Bentonit, Kataliz, Karakterizasyon, Sütunlanmış killer

\section{Characterization of Various Cation Exchanged and Pillared Artvin Bentonites and Their Use as a Catalyst in a Selected Organic Reaction}

\begin{abstract}
In this study, the catalytic activities of raw, some metal cations exchanged $\left(\mathrm{Fe}^{3+}\right.$ and $\left.\mathrm{Cu}^{2+}\right)$ and $\mathrm{Fe}-$ and $\mathrm{Al}-$ pillared Artvin bentonite samples as a catalyst for acetalization reaction of benzaldehyde with 2, 3-butanediol were investigated. The structural and physicochemical properties of clay samples were examined by using XRay powder diffraction (XRD), scanning electron microscope (SEM), Fourier Transform infrared (FTIR) and surface area measurement techniques. The yield of this organic reaction in the presence of $\mathrm{Cu}$-bentonite and $\mathrm{Al}$ pillared bentonites were found as very low whereas Fe-bentonite and Fe-pillared bentonite catalysts showed 60 and $63 \%$ yield in acetalization under same conditions, respectively. This study showed that modified Artvin bentonite samples which is the one member of Turkey's important local and natural sources can be used as catalyst in the selected organic reaction and their utilization in industrial process reactions in small scale.
\end{abstract}

Keywords: Artvin Bentonite, Catalysis, Characterization, illared clays, 
1. Giriş

Geçmişten günümüze kadar birçok reaksiyonun katalizlenmesinde çok farklı katalizörler ve kataliz yöntemleri kullanılmasına rağmen, son zamanlarda yapılan çalışmalar heterojen kataliz sisteminde yer alan ucuz, etkili ve çevre dostu özelliklere sahip katalizörlerin sentezlenmesi ve karakterizasyonu üzerine yoğunlaşmıştır (Carrado, 1986; Tomul, 2012). Homojen katalizde katalizörün buharlaştırılması ya da diğer teknikler ile ayrılması gibi zor ve maliyetli işlemler, heterojen katalizde katı katalizörün sadece basit bir filtrasyonla uzaklaştırılabilmesiyle gerçekleştirilebilmektedir. Ayrıca homojen katalizin daha yüksek maliyeti yanında, çevresel ve yeniden kullanılabilirlilik ile ilgili sıkıntıları, bilimsel araştırma gruplarını çevre dostu ve daha ekonomik yeni endüstriyel heterojen sistem katalizörlerini geliştirmeye yönlendirmiştir. Bugüne kadar yapılmış birçok çalışma büyük yüzey alanlı, ucuz, zehirli madde içermeyen, çeşitli moleküllerle etkileşime girebilecek çok sayıda etkin aktif merkezleri bulunan, termal ve mekanik kararlığa sahip kil ve kil minerallerinin katalizör olarak bu amaca hizmet edebileceğini ortaya koymuştur (Balogh, 1992; Izumi, 1992). Kataliz reaksiyonlarında kil ve kil minerallerinin katalitik etki göstermesinde genellikle kristal köşelerinin üzerinde bulunan Brønsted ve Lewis asit merkezleri barındıran asidik yüzeyleri birincil öneme sahiptir (Vaccari, 1998). Aynı zamanda kil minerallerinin tabaka yüzeyi ve kenar kusurları (çatlak, kırıklar vb.) Brønsted veya Lewis asit merkezleri olarak davranır (Varma, 2002). Kil ve kil minerallerindeki bu aktif merkezlerin daha etkin hale getirebilecek şekilde çeşitli kimyasal veya fiziksel işlemlerle modifiye edilebilmesi ve bu merkezlerin birçok yeni organik reaksiyonu katalizleyebilmesinin yolunu açmıştır (Belkhadem, 2006; Carriazo, 2007). Kil ve kil minerallerinin 1sıl, çeşitli inorganik/organik asitlerle, metal ve polimerik metal iyonları ile etkileşmesine dayalı çeşitli aktivasyon işlemleri, iç ve diş yüzey asidik merkezlerinin sayısını ve katalitik etkinliğini artırmaktadır (Steudel, 2009; Nagendrappa, 2011). Kil ve türevlerinin bu amaç için tercih edilmesinde kataliz reaksiyonlarında oluşan ürün ortamından kolaylıkla uzaklaştırılabilmesi, birden fazla kez kullanılabilmesi, kimyasal olarak zararsız ve çevre dostu olmasının da büyük payı vardır (Anastas, 2001; Zhou, 2011).

$\mathrm{Bu}$ çalışmada, ülkemizin doğal kaynakları arasında yer alan Artvin bentonitinin ön bir saflaştırılma işleminden geçirilmiş ham halinin ve bu halin çeşitli metal katyonları $\left(\mathrm{Fe}^{3+}\right.$ ve $\left.\mathrm{Cu}^{2+}\right)$ değiştirilmiş ve anorganik polimerik metal iyonları ile ( $\left.\left[\mathrm{Al}_{13} \mathrm{O}_{4}(\mathrm{OH})_{24}\left(\mathrm{H}_{2} \mathrm{O}\right)_{12}\right]^{+7}, \quad\left[\mathrm{Fe}(\mathrm{OH})_{3-\mathrm{x}}\right]_{\mathrm{n}}{ }^{\mathrm{nx}+}\right)$ sütunlanmış biçimlerinin benzaldehitin 2,3bütandiol ile asetalleşme reaksiyonundaki katalitik aktiviteleri araştırıldı. Ayrıca bu numunelerin X-1şınları toz kırınım (XRD), Fourier Transform infrared (FTIR), taramalı elektron mikroskobu (SEM) ve yüzey alanı ölçüm teknikleri (yüzey alanı ve gözeneklilik) yardımıyla karakterizasyonları gerçekleştirildi.

\section{Materyal ve Metot}

İlk olarak deneysel çalışmalarda kullanılmak üzere doğal olarak elde edilen ham Artvin bentonit kil kayaları, değirmende öğütülüp elendikten sonra dekantasyon ve fiziksel ayırma yöntemleri ile suda çözünen ve gözle teşhis edilebilen safsızlıklarından arındırıldı. Ardından $105^{\circ} \mathrm{C}$ de 12 saat kurutulan ve öğütülen kil numunesi içindeki organik safsızlıkların uzaklaştırılması amacıyla $\mathrm{H}_{2} \mathrm{O}_{2}$ 
çözeltisiyle muamele edildi. Son olarak kurutulan kil numunesi mekanik öğütücü yardımıyla tekrar öğütüldü ve istenen tanecik boyutunun elde edilmesi için otomatik elekten geçirildi ve diğer işlemler için koyu renkli, nemden arındırılmış kapaklı cam şişelerde saklandi.

\subsection{Metal Katyon Değiştirilmiş Kil Örneklerinin Hazırlanması}

$1 \mathrm{~g}$ kil numunesi $0,5 \mathrm{M} \mathrm{Fe}^{3+}$ ve $0,5 \mathrm{M} \mathrm{Cu}^{2+}$ içeren çözeltilerine ayrı ayrı eklendi ve bu süspansiyonlar oda sicaklığında ve 1 gün karıştırıldı (Tabak, 2003; Tomul, 2012). İşlem sonunda reaksiyon ortamından süzme yolu ile alınan kil numuneleri saf su ile iyice y1kandiktan sonra, $105^{\circ} \mathrm{C}$ de kurutulup ögütüldü, belirli bir tanecik boyutunda olacak şekilde elendi. Tam bir katyon değişimi sağlanabilmesi için bu işlemler $3 \mathrm{kez}$ tekrarlandı. Bu metal katyonları değiştirilmiş örnekler kataliz işlemlerinde ve karakterizasyon analizlerinde kullanmak amaciyla koyu renkli, nemden arındırılmış kapaklı cam şişelerde saklandı.

\subsection{Polimerik Metal Katyon Çözeltilerin Hazırlanması}

Polimerik Al ve Fe metal katyonları işleme çözeltileri; alüminyum ve demir tuzu çözeltilerinin $\mathrm{NaOH}$ çözeltisi ile $\mathrm{OH} / \mathrm{Al}$ ve $\mathrm{OH} / \mathrm{Fe}$ oranları 2 olacak şekilde ve $60^{\circ} \mathrm{C}$ de 5 gün karıştırılmaları ile hazırlandı (Tabak, 2003, 2007).

\subsubsection{Polimerik Metal Katyon Değiştirilmiş (Sütunlanmış) Kil Örneklerinin Hazırlanması}

Kurutulmuş ve elenmiş $1 \mathrm{~g}$ Artvin-bentonit kili içeren \% 2'lik iki farklı süspansiyona Alve Fe- işleme çözeltileri sırasıyla $1 / 9 \mathrm{~g}$ kil/mmol Al ve 1/9 g kil/mmol Fe oranında olacak şekilde ayrı ayrı eklendi, bu süspansiyonlar sabit bir karıştırma hızında, $60^{\circ} \mathrm{C}$ de yaklaşık 17 saat karanlıkta karıştırıldı, ardından süspansiyonların süzülmesi ile elde edilen katı numunelerin 400 ${ }^{\circ} \mathrm{C}$ de 3 saat kalsine edilmesiyle Al-sütunlu ve Fe-sütunlu bentonit numuneleri elde edildi (Hutson, 1999; Tabak, 2003, 2007).

\subsection{Sentezlenen Katalizörlerin Katalitik Etkinliklerinin benzaldehitin 2, 3- bütandiol ile asetalleşme reaksiyonunda Test Edilmesi}

Sentezlenen katalizörlerin katalitik özelliklerinin belirlenmesi için seçilen organik reaksiyon aşağıda sunulmuştur.

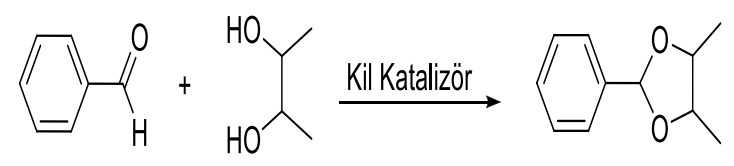

Şema 1 Benzaldehitin sentezlenen killerin katalizörlüğünde 2,3-bütandiol ile asetalleştirilmesi

5 mL'lik kapalı bir tüpte $2 \mathrm{~mL}$ diklorometan içerisinde hazırlanan benzaldehit $(204 \mu \mathrm{L}, 2$ mmol) ve 2,3-bütandiol (365 $\mu \mathrm{L}, 4 \mathrm{mmol}$ ) çözeltisine $40 \mathrm{mg}$ katalizör ilave edildi ve karışım $40{ }^{\circ} \mathrm{C}$ 'de 12 saat karıştırıldı. Oda sıcaklığına soğutulan reaksiyon karışımına iç standart olarak 4-metoksiasetofenon $(30 \mathrm{mg}$, $0,2 \mathrm{mmol}$ ) ilave edildi. Karışım $10 \mathrm{~mL}$ diklorometan ile seyreltildi ve süzülerek katalizörden ayrıldı. Daha sonra $5 \mathrm{~mL}$ su ilave edilen karışım diklorometan $(2 \times 10 \mathrm{~mL})$ ile ekstrakte edildi, organik fazlar birleştirildi, $\mathrm{Na}_{2} \mathrm{SO}_{4}$ ile kurutuldu ve çözücü evaporatörde uzaklaştırıldı. Elde edilen bileşiğin kimyasal yapıs1, miktarı ve verimi NMR tekniği yardımıyla belirlendi.

\section{5 Örneklerin Karakterizasyon İşlemleri}


Örneklerin ATR-FTIR spektrumları Thermo Nicolet 6700 spektrofotometre ile $4 \mathrm{~cm}^{-1}$ çözünürlükte $4000-400 \mathrm{~cm}^{-1}$ bölgesinde ölçülmüştür. XRD profilleri ortam sicakliklarında PANalytical Empyrean difraktometre üzerinde $\mathrm{Ni}$ filtrelenmiş $\mathrm{CuK}_{\alpha}$ radyasyonunu kullanarak $(\lambda=1.54050 \AA ; 45$ $\mathrm{kV}$ ve $40 \mathrm{~mA}$ ) alınmıştır. Numunelerin SEM / EDX analizleri alan emisyon taramalı elektron mikroskobu (Quanta FEG 450-FEI) kullanılarak yapılmıştır. Azot adsorpsiyon / desorpsiyon izotermleri $77 \mathrm{~K}$ da $\left(-196^{\circ} \mathrm{C}\right)$ $0.05<\mathrm{P} /$ Po $<1.00 \mathrm{k}$ ssmi basınç aralığında Quantachrome Autosorb-IQ-2 analizörü ile (Florida, ABD) alınmıştır. Örnek yüzeyleri ölçümlerden önce 3 saat $100^{\circ} \mathrm{C}^{\prime}$ de vakumda desorbe edilerek yüzey temizlenmesi sağlanmıştır.

\section{BULGULAR VE TARTIŞMA}

\subsection{FTIR Verileri}

Ham, metal katyon değiştirilmiş $\left(\mathrm{Fe}^{3+}\right.$ ve $\left.\mathrm{Cu}^{2+}\right)$ ve $\mathrm{Al}-$ ve $\mathrm{Fe}$-sütunlanmış bentonit numunelerinin IR spektrumları Şekil 1 (ae)'de verilmiştir. Metal katyon değiştirilmiş kil numunelerinin IR spektrumları ham Artvin Bentonitinin IR spektrumu ile karşılaştırıldığında; metal katyonu etkileştirilmesiyle kilin $~ 3430$ ve $1635 \mathrm{~cm}^{-}$ ${ }^{1}$ deki suyun $\mathrm{OH}$ gerilme ve eğilme piklerinin; 1450-1382 $\mathrm{cm}^{-1}$ deki kil dişı bileşenlerin piklerinin etkilendiği görülmektedir (Şekil 1 a-c). Özellikle bentonitin su moleküllerine ait geniş yayvan $\mathrm{H}-\mathrm{O}-\mathrm{H}$ gerilme ve eğilme piklerinde görülen kaymalar, bilhassa $\mathrm{Cu}$ bentonit için yeni piklerin meydana gelmesi, iç tabaka boşluğuna dâhil olan $\mathrm{Fe}^{3+}$ ve $\mathrm{Cu}^{+2}$ katyonlarının su molekülleri tarafindan sarılmasına bağlı olarak oluşan yeni bir su molekülleri ağ örgü yapısına işaret etmektedir [4]. Ayrıca $\mathrm{Fe}^{+3}$ ve $\mathrm{Al}^{3+}$ 'e bağlı $\mathrm{OH}$ eğilme pikinde görülen değişim de bu sonucu desteklemektedir. Bunlara ilaveten $\sim 1447 \mathrm{~cm}^{-}$ ${ }^{1}$, de ki pikin gözden kaybolması katyonik yer değiştirmelere bağlı olarak kil dışı bileşenlerinde bu süreçten etkilendiğini ortaya koymaktadır. Tüm bu sonuçlar değerlendirildiğinde, metal katyonları ile kil etkileşme mekanizmasının $\mathrm{Fe}^{3+}$ ve $\mathrm{Cu}^{2+}$ iyonlarıyla iç tabakadaki değiştirilebilir katyonların yer değiştirmesi ve değişen katyonların çevresini farklı bir yapılanma ile su moleküllerinin sarması şeklinde olduğunu ve bu mekanizmadan kil dişı diğer bileşenlerinde etkilendiğini göstermektedir. Ham bentonitin IR spektrumu, polimerik çözeltiyle muamele edildikten ve akabinde kalsinasyon uygulandiktan sonra sentezlenen polimerik Al ve Fe metal katyon değiştirilmiş bentonitlerin IR spektrumları ile karşılaştırıldığında, $1031 \mathrm{~cm}^{-1}$ 'deki Si-O-Si gerilme pikinin yaklaşık $1035 \mathrm{~cm}^{-1}$ 'e kaydığ ve ayrıca $798 \mathrm{~cm}^{-1}$, deki serbest silika pikinin etkilendiği görülmektedir (şekil $1 \mathrm{~d}-\mathrm{e}$ ). Bunlara ilaveten polimerik $\mathrm{Al}$ ve $\mathrm{Fe}$ metal katyon değiştirilmiş bentonitlerin IR spektrumlarında $468 \mathrm{~cm}^{-1}$, deki Si-O-Si deformasyon pikinin $471 \mathrm{~cm}^{-1}$,e kaydığı; polimerik Al metal katyon değiştirilmiş bentonitlerin IR spektrumlarında $522 \mathrm{~cm}^{-1}$ deki Al-O-Si deformasyon pikinin yaklaşık $526 \mathrm{~cm}^{-1}$ 'e kaydı̆̆ 1 tespit edilmektedir. Tüm bu değişimler işleme kaynaklı protonlar vasıtasıyla oluşan silanol gruplarının varlığına ve ayrıca $913 \mathrm{~cm}^{-1}$ deki $\mathrm{Al}^{+3}$ bağlı $\mathrm{OH}$ deformasyon pikindeki şiddet kaybı da kalsinasyonla birlikte kısmen de olsa hem kilin hem de işlemenin dehidroksilasyonuna atfedilebilir. 


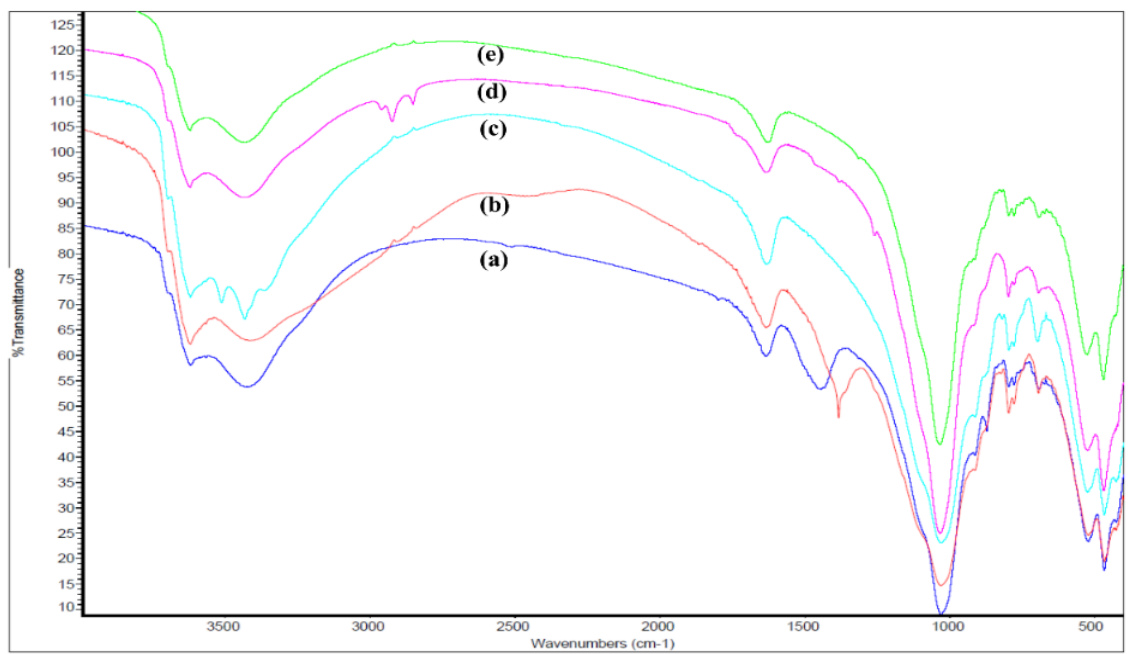

Şekil 1. Ham bentonitin (a), Fe-bentonitin (b), Cu-bentonitin (c), Fe-sütunlu (d) ve Al-sütunlu (e) Bentonitlerin FTIR spektrumları

\subsection{XRD Verileri}

Tablo 1'de ham, Fe-, Cu-bentonit, Alsütunlu ve Fe-sütunlu bentonitlerin temel boşluk değerleri ( $\left.\mathrm{d}_{001}\right)$ verilmiştir. $\mathrm{Fe}^{3+}$ katyonunun bentonit tabakaları arasına girmesiyle ham bentonitte $13,26 \AA$ tabakalar arası mesafe 11,87 $\AA$ değerine düştüğü görülmektedir. Cu-bentonit numunesinde ise bu değer 11,09 $\AA$ olarak ölçülmüştür. Katyonların yer değiştirilmesiyle ham bentonitin tabakaları arasında bir daralma söz konusudur. $\mathrm{Bu}$ sonuç FTIR yorumlarında belirtildiği üzere metal katyonları ile kilin etkileşmesinde, demir ve bakır katyonlarının tabakalar arasına yer değiştirilebilir katyonlarla yer değiştirmek suretiyle girdiğini ve bu yerleşmenin akabinde katyon çevresinde yeni bir su örgüsünün oluştuğunu desteklemektedir.

Al-sütunlanmış ve Fe-sütunlanmış bentonitlerin $\mathrm{d}_{001}$ değerleri sırasıyla 17,88 ve 29,95 $\AA$ olarak tespit edilmiştir. Bu durum polimerik metal katyonlarının bentonite tabakaları arasına dâhil olmasıyla ve akabinde bu polimerik katyonun termal etkiyle dehidrasyon ve dehidroksilasyonun ardından metal-oksit sütunlarına dönüşümünü ortaya koymaktadır (Hutson, 1999; Tabak, 2007).

Tablo 1. Ham, Fe-, Cu-bentonit, Al- ve Fe-sütunlu bentonitlerin temel boşluk (do01) değerleri

\begin{tabular}{lc}
\hline Numune & $\mathrm{d}_{001}(\AA)$ \\
\hline Ham bentonit & 13,26 \\
\hline Fe-bentonit & 11,87 \\
\hline Cu-bentonit & 11,09 \\
\hline Al sütunlu-bentonit & 17,88 \\
\hline Fe sütunlu-bentonit & 29,95 \\
\hline
\end{tabular}




\subsection{SEM Verileri}

Şekil 2 (a-e)' de ham, Fe-, Cu-bentonit, Alsütunlu ve $\mathrm{Fe}$-sütunlu bentonit örneklerinin SEM görüntüleri verilmiştir. Ham bentonitin SEM görüntüsünde ilk göze çarpan kilin tabakalı yapısının net bir şekilde görülmesidir (şekil 2 a). Bu tabakalı yapının hem metal hem de polimerik $\mathrm{Al}$ ve Fe metal katyon değiştirilmiş bentonit örneklerinde korunduğu göze çarpmaktadır (şekil 2 b-e). Bu tabakalı yapı $\mathrm{Cu}$-bentonit örneğinde sanki daha incelmiş bir tabakalı bir yapı izlenimi vermekteyken, özellikle Al işlemeli bentonit de ise genişlemiş bir yapıyı andırmaktadır.
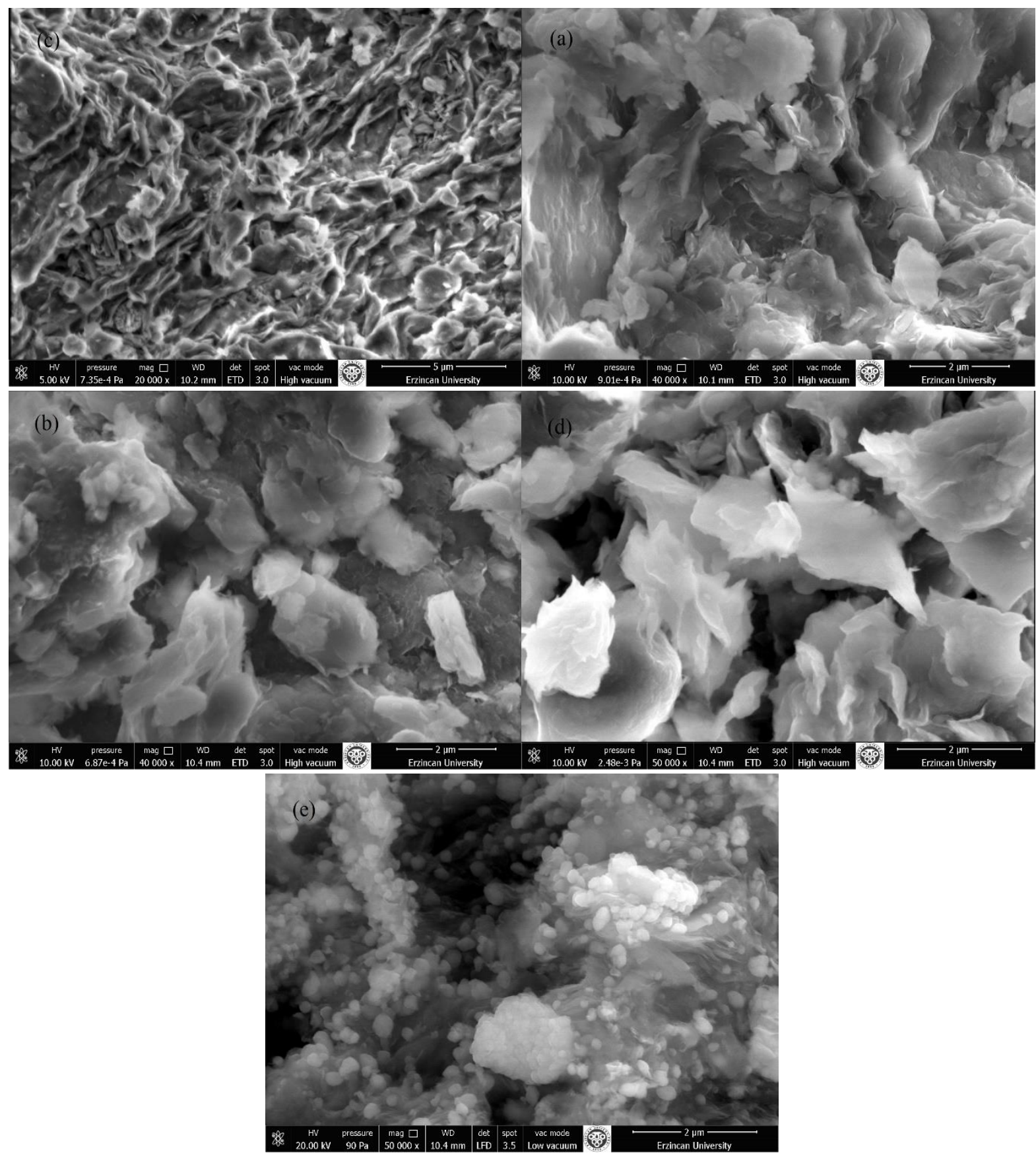

Şekil 2. Ham bentonitin (a), Fe-bentonitin (b), Cu-bentonitin (c), Al-sütunlu (d) ve Fe-sütunlu (e) Bentonitlerin SEM görüntüleri 


\subsection{Adsorpsiyon-Desorpsiyon Verileri}

Ham, Fe-, Cu-bentonit, Al-sütunlu ve Fesütunlu bentonit numunelerinin adsorpsiyon-desorpsiyon izotermlerinden elde edilen yüzey alanları, gözenek tipi, hacmi ve alanları Tablo 2'de verilmiştir. BET yüzey alanı $\left(\mathrm{S}_{\mathrm{BET}}\right)$; mikro- ve mezogözenek hacimleri $\left(\mathrm{V}_{\text {mikro }}, \mathrm{V}_{\text {mezo }}\right)$ ve alanları $\left(\mathrm{S}_{\text {mikro, }}, \mathrm{S}_{\text {mezo }}\right)$ ve toplam gözenek hacimleri ( $\mathrm{V}_{\text {toplam}}$ ) olarak gösterilmiştir.

Tablo 2. Ham, Fe-bentonit, $\mathrm{Cu}$-bentonit, Al-sütunlu ve Fe-sütunlu bentonit numunelerinin BET yüzey alanı ve gözenek dağılım sonuçları

\begin{tabular}{cccccccc}
\hline Örnek & $\mathrm{S}_{\mathrm{BET}}\left(\mathrm{m}^{2} / \mathrm{g}\right)$ & $\begin{array}{c}\mathrm{S}_{\text {mikro }} \\
\left(\mathrm{m}^{2} / \mathrm{g}\right)\end{array}$ & $\begin{array}{c}\mathrm{S}_{\text {mezo }} \\
\left(\mathrm{m}^{2} / \mathrm{g}\right)\end{array}$ & $\begin{array}{c}\mathrm{V}_{\text {toplam }} \\
\left(\mathrm{cm}^{3} / \mathrm{g}\right)\end{array}$ & $\begin{array}{c}\mathrm{V}_{\text {mikro }} \\
\left(\mathrm{cm}^{3} / \mathrm{g}\right)\end{array}$ & $\begin{array}{c}\mathrm{V}_{\text {mezo }} \\
\left(\mathrm{cm}^{3} / \mathrm{g}\right)\end{array}$ & $\begin{array}{c}\text { Ortalama } \\
\text { Gözenek } \\
\text { Cap1 }(\mathrm{nm})\end{array}$ \\
\hline Ham bentonit & 116,328 & 32,838 & 41,906 & 0,239 & 0,016 & 0,199 & 3,794 \\
\hline Fe-bentonit & 116,243 & 48,331 & 32,550 & 0,131 & 0,023 & 0,087 & 3,969 \\
\hline Cu-bentonit & 115,523 & 31,356 & 35,012 & 0,137 & 0,016 & 0,090 & 3,969 \\
\hline Al sütunlu-bentonit & 132,138 & 50,769 & 38,377 & 0,241 & 0,024 & 0,192 & 0,718 \\
\hline Fe sütunlu-bentonit & 107,730 & 13,639 & 50,660 & 0,172 & 0,006 & 0,139 & 3,202 \\
\hline
\end{tabular}

Tablo 2'deki deneysel veriler dikkatle incelendiğinde ilk olarak hiçbir işlem görmemiş ham bentonitin, Al-sütunlu bentonitten daha düşük yüzey alanı değerine sahip olduğu göze çarpmaktadır. $\mathrm{Bu}$ sonuç ham bentonitin işlenmesinin hem yüzey alanının artmasında hem de gözenek yapısının gelişmesinde büyük bir etki oluşturduğu şeklinde yorumlanabilir. Tablo 2'de BET yüzey alanları, mikro ve mezogözenek alanları ve hacimleri ele alındığında, metal katyon $\left(\mathrm{Fe}^{3+}\right.$ ve $\left.\mathrm{Cu}^{2+}\right)$ değiştirilmiş bentonit numunelerinin yüzey alanları ile ham bentonitin yüzey alanı birbirine çok yakın olmakla birlikte; $\mathrm{Cu}-$ bentonitte ham bentonite göre yapıda hem mikrogözenek hemde mezogözeneklerde bir azalma gözlenirken, Fe-bentonit ise mikrogözeneklerde az da olsa bir artış, mezogözeneklerde ise bir azalma görülmektedir. Sütunlanmış bentonitlerde özellikle Al sütunlu-bentonitte ise spesifik yüzey alanı ve özellikle mikrogözenek alanı ve hacminde ve ayrica toplam gözenek hacminde bir artış tespit edilmektedir. $\mathrm{Bu}$ durum polimerik metal katyonun kil tabakaları arasına girmesi ve bu polimerik katyonun termal etkiyle dehidrasyon ve dehidroksilasyonun ardından metal oksit sütunlarına dönüşümünü bağlı olarak oluşan yeni gözenek yapısını teyit etmektedir. Ham bentonitte baskın olan hem mikro hem de mezogözenek yapısı sütunlu bentonitte biraz daha mikrogözenek tarafina doğru kaydığı görülmektedir. Ayrıca sütunlamayla ortalama gözenek çapındaki büyük oranda azalmada bu sonucu desteklemektedir.

\subsection{Kataliz Verileri}

Sentezlenen katalizör kil numunelerinin benzaldehitin 2, 3-bütandiol ile asetalleşme reaksiyonundaki katalitik etkileri araştırıldı. 
Aşağıda verilen tepkimenin \% dönüşüm ve $\%$ verimleri 4-metoksi asetofenonun iç standart olarak kullanılmasiyla NMR verilerinden hesaplanmış ve her bir kil katalizörünün kullanıldığı tepkime için bu değerler Tablo 3'de verilmiştir. Tablo 3 deki \% verim değerleri incelendiğinde; ham bentonitin katalizör olarak kullanıldığı tepkimede herhangi bir asetalleşme ürününün gözlenmediği, $\mathrm{Cu}$-bentonit ve $\mathrm{Al}$ sütunlu-bentonit katalizörlü reaksiyonlarda ise çok az ürün oluştuğu (sırasıyla \% 2 ve 5) belirlenmiştir. Bununla birlikte, Fe-bentonit ve $\mathrm{Fe}$ sütunlu-bentonit katalizörlerinin kullanıldığı tepkimeler için ürün verimlerinin hayli artarak sirasıyla \% 60 ve \% 63 olduğu tespit edilmiştir. Bu değerler literatürde sentezlenen dioksalan verimleri ile uyum içindedir (Devendrapratap, 2004; Bahranowski, 2015). Diğer taraftan \% dönüşüm verileri incelendiğinde ham, $\mathrm{Cu}$ bentonit ve $\mathrm{Al}$ sütunlu-bentonitlerin kullanıldığı tepkimelerde asetalleşme ürünü hiç veya çok az oluşmasına rağmen, benzaldehitin yapısı belirlenmemiş ürün veya ürünlere dönüştüğü NMR spektrumlarından tespit edilmiştir (Şekil 37). Fe-bentonit ve $\mathrm{Fe}$ işli- bentonit katalizörlerinin kullanıldığı tepkimelerde ise yan ürün veya ürünlerin oluşmadığı ve sırasıla $\% 93$ ve $\% 95$ dönüşümle asetalleşme reaksiyonu gerçekleşmiştir. Literatürde bu model asetalleşme tepkimesinin Lewis asit katalizörlügünde yürüdüğü bilinmektedir. Öyleyse, bu veriler 1şığında Fe-bentonit ve $\mathrm{Fe}$ sütunlubentonitlerin yeterli miktarda Lewis asit merkezlerine sahip olduğu ve bu asetalleşme tepkimesi için uygun katı katalizörler olarak kullanılabileceği belirlenmiştir. Buna karşın, ham, Cubentonit ve $\mathrm{Al}$ işli-bentonitlerin yapısında ise yeterli ve uygun miktarda Lewis asit merkezlerinin olmadiğı ve bu model asetalleşme tepkimesinde katalizör olarak kullanılamayacağı ve başka ürün veya ürünlerin oluştuğu tepkimeler için katalitik aktivitesinin araştırılabileceği değerlendirilmektedir.

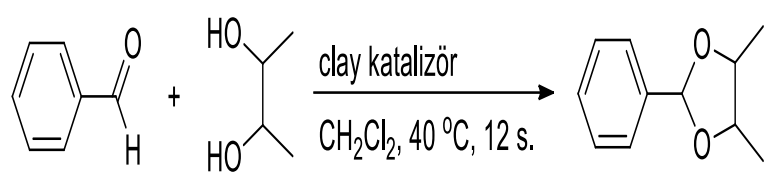

Şema 2. benzaldehitin 2, 3-bütandiol ile asetalleşme reaksiyonu

Tablo 3. Benzaldehitin 2, 3-bütandiol ile asetalleşme reaksiyon için; Ham, Fe-bentonit, Cubentonit, Al-sütunlu ve Fe-sütunlu bentonit katalizör numunelerinin katalitik özellikleri

\begin{tabular}{cccc}
\hline Deney & Katalizör & $\begin{array}{c}\text { Dönüşüm } \\
{[\%]}\end{array}$ & Verim [\%] \\
\hline 1 & Ham bentonit & 65 & 0 \\
\hline 2 & Fe-bentonit & 93 & 60 \\
\hline 3 & Cu-bentonit & 65 & $2<$ \\
\hline 4 & Al sütunlu-bentonit & 70 & 5 \\
\hline 5 & Fe sütunlu-bentonit & 95 & 63 \\
\hline
\end{tabular}




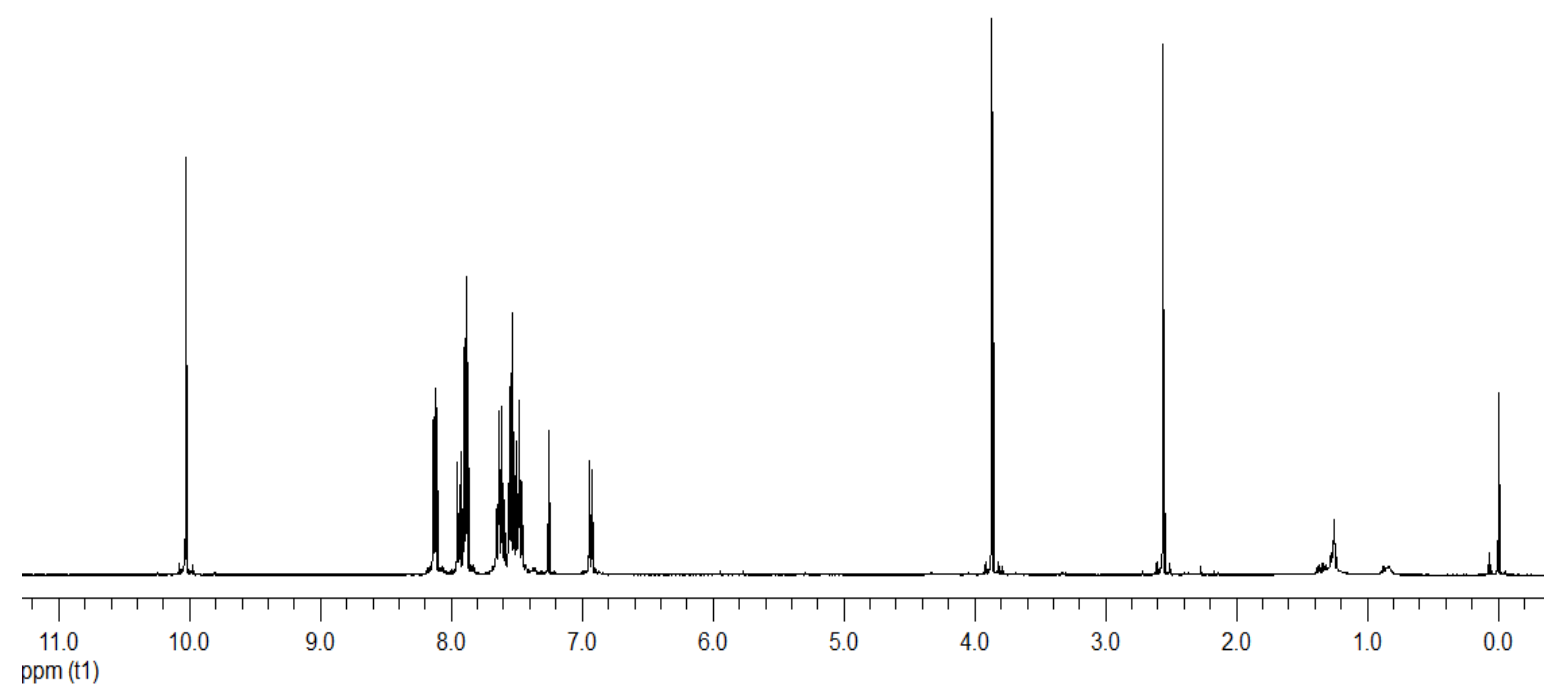

Şekil 3. Ham bentonitin asetalleşme reaksiyonunu katalizlemesini belirlemeye yönelik alınan NMR spektrumu

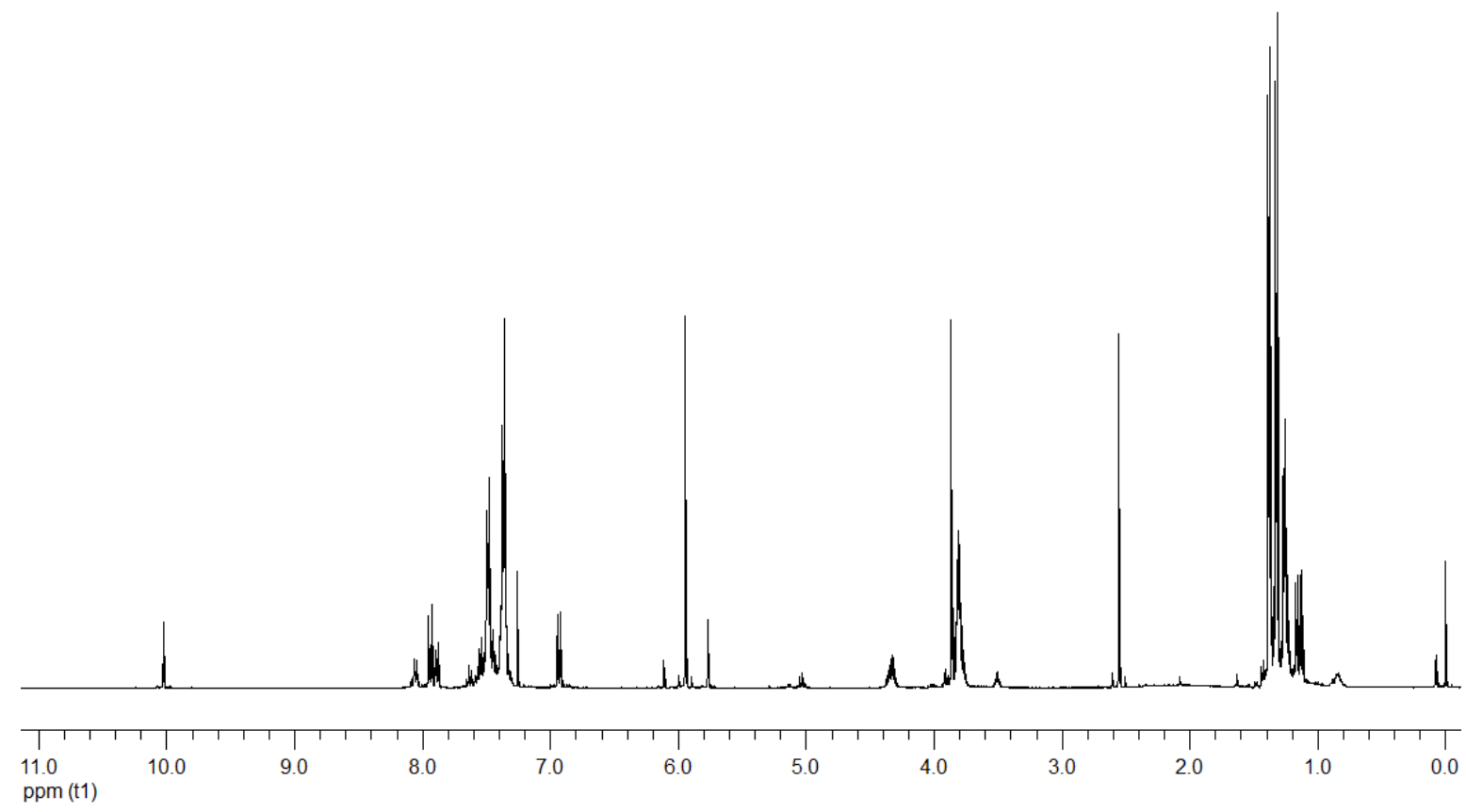

Şekil 4. Fe-bentonitin asetalleşme reaksiyonunu katalizlemesini belirlemeye yönelik alınan NMR spektrumu 


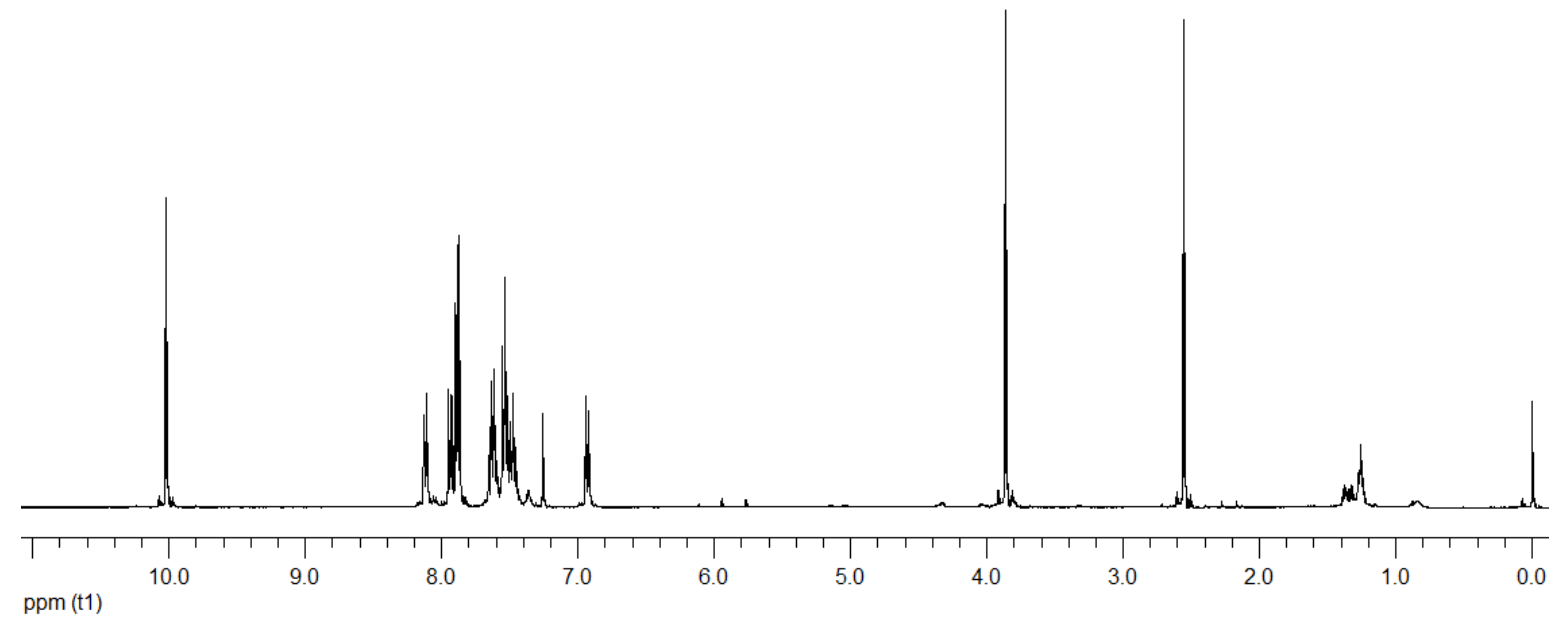

Şekil 5. Cu-bentonitin asetalleşme reaksiyonunu katalizlemesini belirlemeye yönelik alınan NMR spektrumu

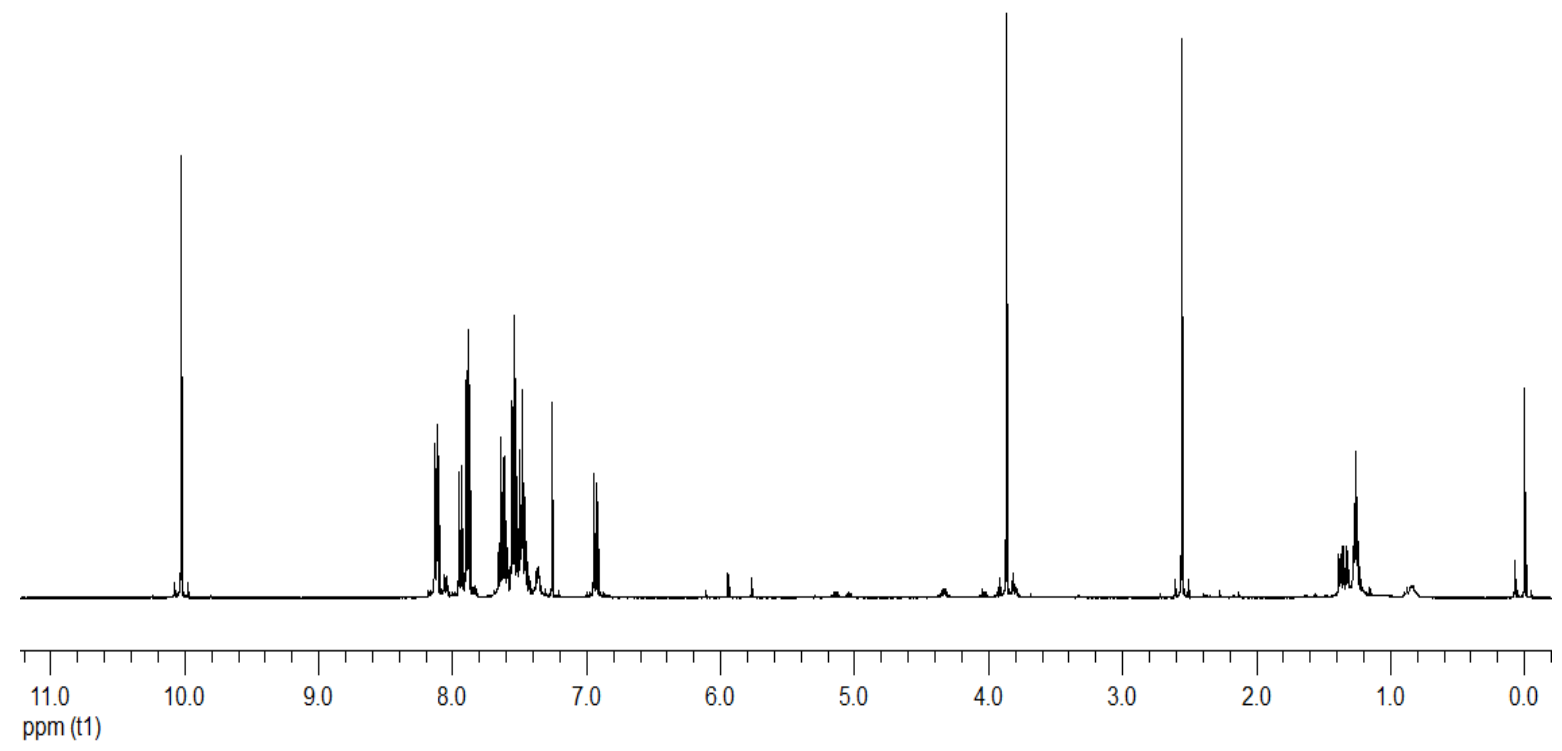

Şekil 6. Al-sütunlu bentonitin asetalleşme reaksiyonunu katalizlemesini belirlemeye yönelik alınan NMR spektrumu 


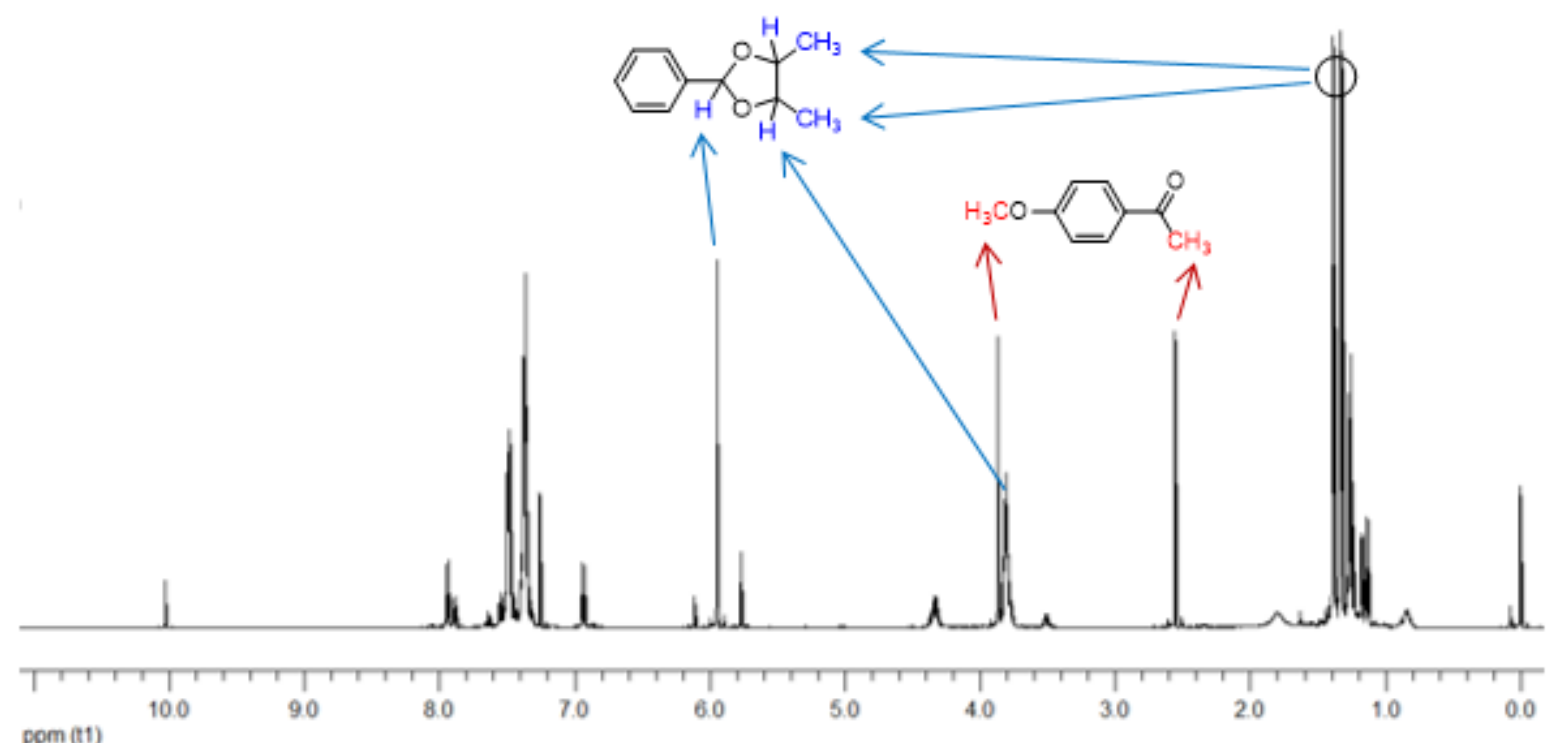

Şekil 7 Fe-sütunlu bentonitin asetalleşme reaksiyonunu katalizlemesini belirlemeye yönelik alınan NMR spektrumu

Oluşan ürünün (4,5-dimetil-2-fenil-1,3dioksolan $\left.{ }^{\mathrm{x}}\right){ }^{1} \mathrm{H}$ NMR $\left(\mathrm{CDCl}_{3}, 400 \mathrm{MHz}\right)$ : $\delta=1.33$ (d, $J=5.8 \mathrm{~Hz}, 2 \mathrm{H}), 1.39$ (d, $J=5.8 \mathrm{~Hz}$, $2 \mathrm{H}), 3.76-3.84(\mathrm{~m}, 2 \mathrm{H}), 5.95(\mathrm{~s}, 1 \mathrm{H}), 7.35-$ $7.40(\mathrm{~m}, 3 \mathrm{H}) 7.48-7.50 \mathrm{ppm}(\mathrm{m}, 2 \mathrm{H})$;

\section{SONUÇLAR}

Metal katyon değiştirilmiş bentonit numunelerinin IR ve XRD verileri $\mathrm{Fe}^{3+}$ ve $\mathrm{Cu}^{2+}$ katyonlarıyla iç tabakadaki değiştirilebilir katyonların yer değiştirdiği ve değişen katyonların çevresinin farklı bir yapılanma ile su moleküllerinin sarması şeklinde olduğunu göstermiştir. Al-sütunlu ve Fe-sütunlu bentonitlerde ise isısal etkiyle oluşan metaloksit sutunlarının kilin tabakalar arasını genişlettiğini ve işleme kaynaklı protonlar vasıtasıyla oluşan silanol gruplarının varlığına işaret eden $\mathrm{Si}-\mathrm{O}-\mathrm{Si}$ gerilme ve Al-O-Si deformasyon piklerinde kaymalar olduğu tespit edilmiştir. Sütunlu bentonitlerde ortalama gözenek çap1 azalmış ve özellikle ham bentonitteki hem mikro hem de mezogözenek baskın yapının, bu işlenmiş bentonitteki yeni yapıda biraz daha mikrogözenek tarafina doğru kaydığını açıkca görülmektedir. Ham bentonitin katalizör olarak kullanıldı̆̆ tepkimede herhangi bir asetalleşme ürününün gözlenmediği, $\mathrm{Cu}$-bentonit ve $\mathrm{Al}$ işli-bentonit katalizörlü reaksiyonlarda ise çok az ürün oluştuğu, bununla birlikte; Febentonit ve Fe işli-bentonit katalizörlerinin kullanıldığı tepkimeler için ürün verimlerinin hayli yüksek olduğu tespit edilmiştir. Bu durum yeterli miktarda Lewis asit merkezlerine sahip Fe-bentonit ve Fe sütunlu- bentonit katalizörlerinin kullanıldığı tepkimelerde ise yan ürün veya ürünlerin oluşmadığı yüksek verimli bir dönüşümle asetalleşme reaksiyonunun gerçekleştiğini göstermektedir. Sonuç olarak, Fe- ve Fe işli-bentonitlerin yeterli miktarda Lewis asit merkezlerine sahip olduğu ve bu asetalleşme tepkimesi için uygun katı katalizörler olarak kullanılabileceği belirlenmiştir. 


\section{Teșekkür:}

Yazarlar Proje No: FEF-1901-16-12 olan proje kapsamında gerçekleştirilen bu çalışma için Sinop Üniversitesi Bilimsel Araştırma Projeleri Koordinasyon Birimi Koordinatörlügü'ne teşekkür ederler.

\section{KAYNAKLAR}

Anastas P.T., Kirchhoff M.M. and Williamson, T.C. Catalysis as a foundational pillar of green chemistry Applied Catalysis A: General 221; 3-13, 2001.

Bahranowski K., Włodarczyk W., WisłaWalsh E., Gawel, A. et al. [Ti,Zr]-pillared montmorillonite - A new quality with respect to $\mathrm{Ti}$ - and $\mathrm{Zr}$-pillared clays. Microporous and Mesoporous Materials 202; 155-164, 2015.

Balogh M. ve Laszlo P. Organic Chemistry Using Clays. Springer, New York, 1992.

Barrault J., Bouchoule C., Echachoui K., Frini-Srasra N., Trablesi M., and Bergaya F., Catalytic Wet Peroxide Oxidation (CWPO) of Phenol Over Mixed (Al-Cu)Pillared Clays. App. Catal. B: Environ. 15 ; 269-274, 1998.

Barrault J., Tatibouët J. M. and Papayannakos N. Catalytic Wet Peroxide Oxidation of Phenol Over Pillared Clays Containing Iron or Copper Species. Surface Chemistry and Catalysis, 3; 777-783, 2000.

Belkhadem F., Clacens J. M., Bengueddach A., and Figueras F. Acidity and catalytic properties for the alkylation of aromatics of PILCs with mixed oxide pillars prepared from two different bentonites. Applied Catalysis A: General 298; 188-193, 2006.
Carrado K. A., Suib S. L., Skoularikis N. D. and Coughlin R.W. Chromium(III)-Doped Pillared Clays (PILCs). Inorg. Chem., 25; 4217-4221, 1986.

Carriazo J.G. Effect of $\mathrm{Fe}$ and $\mathrm{Ce}$ on $\mathrm{Al}-$ pillared bentonite and their performance in catalytic oxidation reactions. Appl. Catalysis A. 317; 120-128, 2007.

Devendrapratap U. S, Pankajkumar R. S, Shriniwas D. S. Fe-pillared bentonitean efficient catalyst for sulfonylation of arenes using aryl and alkyl sulfonyl chlorides, Tetrahedron Letters. 45; 90799082, 2004.

Hutson N. D., Hoekstra M. J. and Yang R. T. Control of Microporosity of Al2O3Pillared Clays: Effect of $\mathrm{pH}$, Calcination Temperature and Clay Cation Exchange Capacity. Microporous and Mesoporous Materials, 28; 447-459, 1999.

Izumi Y., Urabe K. and Onaka M. Zeolite, Clay, and Heteropoly Acid in Organic Reactions. Kodansha Ltd., Tokyo, 1992.

Jozefaciuk G. and Bowanko G. Effect Of Acid And Alkali Treatments On Surface Areas And Adsorption Energies Of Selected Minerals. Clays and Clay Minerals, 50; 771-783, 2002.

Mnasri S., Hamdi N., Frini-Srasra N. and Srasra E. Acid-base properties of pillared interlayered clays with single and mixed $\mathrm{Zr}-\mathrm{Al}$ oxide pillars prepared from Tunisianinterstratified illite-smectite. Arabian Journal of Chemistry, 10; 1175-1183, 2017

Nagendrappa, G. Organic Synthesis Using Clay and Clay-Supported Catalysts. Appl. Clay Sci. 53; 106-138, 2011. 
Steudel A., Batenburg L.F., Fischer H.R., Weidler, P.G. and Emmerich K. Alteration of swelling clay minerals by acid activation. Appl. Clay Sci. 44; 105-115, 2009.

Tabak, A. Çeşitli Kaolin Yüzeyleri Üzerinde Adsorplanmış Amonyak ve Piridin Türleri. Yüksek Lisans Tezi, Ondokuz Mayıs Üniversitesi Fen-Bilimleri Enstitüsü, Samsun, 1998.

Tabak A. Çeşitli Organo- ve AnorganoKillerin Ara-Yüzey Özelliklerinin FTIR, XRD, BET, UV-Gör, HPLC ve Termik Analiz Teknikleriyle İncelenmesi. Doktora Tezi, Ondokuz Mayıs Üniversitesi FenBilimleri Enstitüsü, Samsun, 2003.

Tabak A., Afsin B., Caglar B., and Koksal E., "Characterization and Pillaring of a Turkish Bentonite (Resadiye)", Journal of Colloid and Interface Science. 313; 5-11, 2007.

Tomul F. Adsorption and catalytic properties of $\mathrm{Fe} / \mathrm{Cr}$-pillared bentonites. Chem. Engin.J. 186; 380-390, 2012.

Vaccari A. Clays and catalysis: a promising future.Appl. Clay Sci. 14; 161-198, 1999.

Vaccari A. Preparation and catalytic properties of cationic and anionic clays.Catalysis Today 41; 53-71, 1998.

Varma, R. S. 2002. Clay and ClaySupported Reagents in Organic Synthesis. Tetrahedron 58; 1235-1255.

Vaughan D.E.W. Pillared Clays. Catalysis Today, 2; 187-198, 1988.

Zhou C.H. An overview on strategies towards clay-based designer catalysts for green and sustainable catalysis Applied Clay Science 53; 87-96, 2011, 